may assume steam which is dry and just saturated to behave as if it were a gas the $\gamma$ of which is I.I3, and steam with 25 per cent. of moisture as if it were a gas the $\gamma$ of which is I.II3. It results that the velocity in the throat delivering steam is never greater than the velocity of sound in such steam as exists in the throat, and the pressure in the throat is never less than $5^{8}$ per cent. of the pressure inside the vessel, however low the pressure of the outside space may be.

Mr. Napier's experiments first directed attention to this phenomenon, and Prof. Osborne Reynolds, in I885 ("Collected Papers," vol. ii. p. 3II), gave the explanation.

Students are still too much influenced by their knowledge of flowing water; they cannot help thinking that the flow of a gas is analogous, whereas in all important particulars the flow of a gas is entirely different from the flow of a liquid. After much unbelief among students of this subject, it is now becoming known that when there is a divergent mouthpiece outside the throat, the velocity of a compressible fluid may become very much greater than the velocity of sound; speeds of 3000 or 4000 feet per second seem to be possible at the ends of the divergent orifices used in the Laval turbine. Some years ago I framed a theory of the injector which seemed reasonable, and yet I found it wrong in its application to experimental results. I now know that it was really a good working theory. It seemed to be wrong really because I could not imagine a velocity of steam greater than that found by Napier, the velocity of sound.

I wish to show that the reasoning of Prof. Osborne Reynolds leads to an explanation of what occurs in an expanding mouthpiece. The motion is steady in the vessel until the narrowest part or throat is reached; in the expanding mouthpiece the motion is turbulent, but perhaps I may be allowed to consider the motion as steady throughout, as this will illustrate what occurs well enough, and turbulent motion mathematics is quite beyond my powers.

If $W$ is the weight of gas passing along a stream tube the cross section of which is $A$, then at a place where the pressure is $p$ we know from the usual reasoning that

$$
\mathrm{W}=\mathrm{A} \sqrt{\frac{2 g \gamma}{\gamma-\mathrm{I}} w_{0} p_{0}\left(\alpha^{2 / \gamma}-\alpha_{1+1} / \gamma\right)}=\mathrm{A} w v
$$

if $w$ is the weight of unit volume of the gas, being $w_{0}$ where $p$ is $p_{0}$ and if $\alpha$ stands for $p / p_{0}$.

Now let us keep W constant, and we are able to calculate the cross section of the stream at any place where $p$ is known.

I sometimes ask the individuals of a class of students to calculate, each of them, a part of such a table as the following:-

Imagine steam in a vessel at $p_{0}=14400$, or Ioo $\mathrm{lb}$. per square inch, to flow towards a throat with an expanding orifice outside; at the following pressures I give the corresponding cross sections $\mathrm{A}$ of a stream tube and the velocity there. It will be seen that where the tube is narrowest the pressure is $57.85 \mathrm{lb}$. per square inch; this is near the narrowest part of the orifice. Beyond this in the expanding part $\mathrm{A}$ increases, the pressure falls, and the velocity becomes greater and greater.

I take a stream tube in which the flow is I $1 \mathrm{~b}$. per second, or $W=I$. These numbers deserve study. It is evident that to get very high speeds the mouthpiece must be much enlarged from the throat, but as rapid enlargement must lead to greater turbulence, velocities much greater than 3000 feet per second ought hardly to be expected.

If we double all the pressures in the table, the values of $\mathrm{A}$ and $v$ there given are right for the case of flow of steam from a vessel where $p_{0}$ is $200 \mathrm{lb}$. per square inch ; about two pounds of steam per second now flows along the tube.

An expanding mouthpiece increases the flow of water, and velocities are less where cross sections are greater; but in the case of air or steam, the total quantity flowing is not increased, and velocities are greater where cross sections are greater.

\begin{tabular}{|c|c|c|c|c|c|}
\hline $\begin{array}{l}\text { 1b. per } \\
\text { sq. in. }\end{array}$ & $\begin{array}{c}\text { A } \\
\text { sq. } \mathrm{ft} .\end{array}$ & $\begin{array}{c}v \\
\text { ft. per sec. }\end{array}$ & $\begin{array}{l}\stackrel{p}{p} \\
\text { lb. per } \\
\text { sq. in. }\end{array}$ & $\begin{array}{c}\text { A } \\
\text { sq. ft. }\end{array}$ & $\begin{array}{c}v \\
\text { ft. per sec. }\end{array}$ \\
\hline 100 & $\infty$ & o & 40 & 0.00524 & 1963 \\
\hline 90 & 0.00732 & 658 & 30 & 0.00599 & 2252 \\
\hline 80 & $0.0054 \mathrm{I}$ & 994 & 20 & 0.00743 & 2654 \\
\hline 70 & 0.00489 & I 245 & 15 & 0.00889 & 2910 \\
\hline 60 & 0.00483 & 1456 & 10 & 0.01170 & 3220 \\
\hline $57 \cdot 85$ & $0.0048 \mathrm{I}$ & 1512 & 5 & 0.01430 & 3506 \\
\hline 55 & 0.00484 & 1573 & $2 \frac{1}{2}$ & 0.03306 & 4214 \\
\hline 50 & 0.00488 & 1708 & & & \\
\hline
\end{tabular}

John Perry.

\section{PROGRESS OF GEOLOGICAL SURVEY OF THE UNITED KINGDOM.}

I $T$ would be impossible to give on one page an epitome of the work done in a year by the Geological Survey, but it may be possible to explain the arrangement of the official summary of progress and to indicate the character and range of the information contaised in it.

By far the greater number of persons who consult it want first of all to learn whether anything new has been published about their own district. We find, therefore, that the information is arranged geographically under the heads England and Wales, Scotland and Ireland, and that subordinate to these there is a reference to districts, not well defined physical or political divisions of permanent importance, but divisions arbitrarily chosen for the purpose of easy reference to the areas over which the work of the year has been carried on.

The descriptions are further classified under the names of the geological formations found in each district.

The most important part of the work deals, of course, with the observations made in the field and recorded on the maps and sections, or described in memoirs and explanations, but the palæontological, petrological and chemical work all receive special notice, as do the products of economic value and the excellent museum connected with, and largely brought together by, the Survey.

All who are engaged in geological teaching or research, or the practical application of the science, must watch the results obtained by the Survey, whether they involve, as proved by Mr. Thomas, a correction of the section across the Towy Valley, or throw light on the relation of the Devonian to the Old Red, as may be seen in Mr. Strahan's work, or furnish material for determining the exact "geological equivalents" of the coal-bearing strata in several distinct and isolated areas, as shown by Mr. Kidston, or data for discussing with $\mathrm{Mr}$. Clement Reid the conditions which prevailed when the deposits were laid down in which man's remains first appear.

The practical man, who has always met with so much courtesy and assistance in the Survey Office, whether he seeks how he may find water or in which direction he might hope to pick up again a lost seam of coal or vein of metal, has always turned to the publications of the Survey for the results of the latest and most careful examination of the district in which he is interested.

NO. 1774 , voL. 68$]$ 
It is, however, difficult for a man of small leisure to search through the maps, sections, explanations, and memoirs to see whether there is anything which immediately concerns him. In the annual report of progress such men find a short account of what has been done and often a forecast of what line of research it is proposed to follow next-as, for example, in the description of the coal-bearing strata in the basin of the Amman.

It would, however, be a mistake to suppose that the results achieved are of interest to geologists only. From the summary of progress just issued, it may be seen that the work appeals to a much wider public than would at first appear. It contains a record of accurate observations on the relation to one another of the great masses of which the earth's crust is made up-very different from the a priori reasoning as to how they ought to behave with which we have so often had to be content. If we turn to the very first page of the introduction, in which the able director of the Survey gives a sketch of what he and his men have done, we read that they have demonstrated that the arrangement of the different kinds of rock proves that there have been movements by which slices of sedimentary and igneous matter, of heavy basic and lighter acidic rock, have been thrust in, so that they now appear in alternating layers over large areas, and further that these earth movements have crushed and kneaded and drawn out the constituents of the rock so that its structure is quite different from that which they have reason to infer it once had from the changes observed as they trace each mass across the country.

The physicist and astronomer will find in the survey publications the results of observations on earth movements recorded by a man like Mr. Harker, who is not only one of the highest authorities in petrography, but also a mathematician of the first order; while geographers will note with interest the inferences which are forced upon clear-headed and experienced observers like Mr. Strahan, who are trained, as few ordinary travellers are, to watch every indication of change of rock structure, and to trace the guiding influence of systems of displacement upon the rivers and other denuding agents which have moulded the surface of the land.

In the Survey memoirs biologists will find treatises, by men like Woodward, Clement Reid, and Lamplugh, dealing with ancient climatal and physical conditions which have varied, as inferred from the flora and fauna as well as from other indications, with the great geologic changes of the earth's crust.

On the staff of the Survey are many men of worldwide reputation who are approaching these large questions from many different points of view, and fully realise what large superstructures may be built up on the facts which they lay down. Carping critics talk of the "uncertainties of geology"; that is because the public is sometimes told what working hypothesis is suggested by evidence which is known to be incomplete. It is not necessary for pioneers to be always repeating the certainties, and the Summary of Progress lets the public follow the work as it is going on.

\section{NOTES.}

THE council of the Royal Meteorological Society has awarded the Symons gold medal to Prof. Julius Hann, of Vienna, in recognition of the valuable work which he has done in connection with meteorological seience. The medal will be presented at the annual meeting of the Society on January 20, 1904.

A nus: of John Dalton, presented to the Manchester Literary and Philosophical Society by Sir Henry E. Roscoe on the occasion of the centenary of the announcement of the atomic theory, was unveiled on October 20. The secretary read the following letter from Sir Henry Roscoe:- "I desire to present to the Literary and Philosophical Society of Manchester a bronze bust of Dr. Dalton, as a memento of the many years of pleasant intercourse which $I$ have in past days spent in converse with its members, and as a recognition of the honour which the Society has done me by electing me as an honorary member, and in bestowing upon me its Dalton Medal. The bust is the work of a distinguished sculptress, Miss Levick, and I believe that all those who have seen it agree with me in esteeming it a powerful and lifelike work of art. It will give me great satisfaction to hear that the Society accept my gift, and that they value the bust as a work of art and as a reminiscence of the donor." The president, in formally unveiling the bust, observed that it was a happy coincidence that this meeting took place on the anniversary of the date when Dalton communicated to the Society his paper on the absorption of gases by water, in which was given the first hint of the atomic theory.

THE zebra stallion Matopo, which has been described and figured by Prof. Cossar Ewart in his book " The Penycuik Experiments," and was the sire of some interesting zebrahorse hybrids, is dead. This zebra was purchased some time ago by Mr. Assheton-Smith, Vaynol Park, Bangor, who was hopeful that he might find it possible to repeat some of Prof. Ewart's experiments, but unfortunately his expectations have not been realised. Whilst retaining the skin, he has presented the skeleton of the zebra to the University College of North Wales, where it will form a handsome addition to the zoological collection. It may also be noted that to this college Prof. W. A. Herdman, F.R.S., of Liverpool, recently made a donation of some fishes from Ceylon and Indo-Malaya which he collected when in the East investigating the pearl fisheries of Ceylon. Prof. D'Arcy Thompson, C.B., Dundee, has also presented a skeleton of the somewhat rare sea otter (Enhydra) from Alaska. By presentation and purchase a valuable zoological collection, which is under the care of Prof. Philip J. White, has gradually been formed at the college.

Dr. DAwson TURner has been awarded a Keith prize by the Royal Scottish Society of Arts for papers upon improved Röntgen apparatus and other electrical matters:

AT an auction sale of rare, valuable and standard books by Messrs. Hodgson and Co., Chancery Lane, on October $2 \mathrm{I}$. a complete set of Curtis's Botanical Magazine, from the commencement in 1787 to the present month, realised the sum of $120 l$.

THE opening meeting of the Institution of Electrical Engineers will be held on November 12, when the premiums awarded for papers read or published during the session 1902-1903 will be presented, and the president, Mr. Robert Kaye Gray, will deliver his inaugural address.

Mr. Marconi, in company with Captain H. B. Jackson, has gone to Gibraltar to carry out further experiments for the Admiralty. It is hoped to be able to open communication with Gibraltar before losing touch with Portsmouth.

Accokding to the daily papers, the Post Office authorities are about to make experiments with the de Forest system of wireless telegraphy. Dr. Lee de Forest has come over 